\title{
Moving the IT Infrastructure to the Cloud
}

\section{(Mudando la infraestructura de TI a la nube)}

\author{
Oswaldo Moscoso-Zea ${ }^{1}$, Joel Paredes-Gualtor ${ }^{1}$, Pablo Saa ${ }^{1}$, Fanny Sandoval ${ }^{1}$
}

\begin{abstract}
:
Cloud computing services are nowadays advertised as an emerging business model. Moreover, these services bring innovative solutions in a more sophisticated competitive market. But, the decision for their adoption could be significantly reduced due to organizations' concerns related to security, privacy, and trust. The challenge involves such questions as where to start, which provider should the company choose or whether it is even worthwhile. Thus, this paper proposes an improved unified framework, based on a previous study where a 6 step process framework was introduced. This improved framework add one new step for security and control after the migration process. At the end, a 7 processes framework is proposed aimed to fulfill organizations' concerns when decide to adopt cloud computing services with a follow-up step. This additional step intends to help IT directors to make sure everything is working properly in a methodological way, in order to achieve a successful cloud computing migration process. An effective solution that is gaining momentum and popularity for competitive organizations.
\end{abstract}

Keywords: cloud computing; cloud services; cloud framework; cloud adoption.

\begin{abstract}
Resumen:
Los servicios de computación en la nube hoy en día se promocionan como un modelo de negocios emergente. Además, estos servicios brindan soluciones innovadoras en un mercado competitivo más sofisticado. Sin embargo, la decisión de su adopción podría reducirse significativamente debido a las preocupaciones de las organizaciones relacionadas con la seguridad, la privacidad y la confianza. El desafío involucra preguntas tales como dónde comenzar, qué proveedor debe elegir la compañía o si vale la pena. Por lo tanto, este documento propone un marco de trabajo unificado y mejorado, basado en un estudio previo donde se introdujo ya un proceso de 6 pasos. Este marco de trabajo mejorado añade un nuevo paso para el control y la seguridad después del proceso de migración. En sí, se propone un marco de trabajo de 7 procesos dirigido a satisfacer las preocupaciones de las organizaciones cuando deciden adoptar servicios de computación en la nube incluido el proceso de seguimiento. Este paso adicional tiene la intención de ayudar a los directores de $\mathrm{Tl}$ a asegurarse que todo funcione correctamente de forma metodológica, a fin de lograr un proceso exitoso de migración de la infraestructura de TI a la nube. Una solución efectiva que está ganando popularidad e impulso dentro de las organizaciones competitivas.
\end{abstract}

Palabras clave: computación en la nube; servicios en la nube; infraestructura en la nube; adopción de la nube.

\section{Introduction}

Technology and information systems have suffered a transformation from being merely support tools to become generators of new business models and enable competitive advantages for organizations. A sound information management and the setting of the right information infrastructures has become a necessity for organizations all over the world. One of the technologies that have evolved through these years and have become indispensable

\footnotetext{
1Universidad Tecnológica Equinoccial, Quito - Ecuador (\{omoscoso, joel.paredes, psaa,
} fanny.sandoval\} @ute.edu.ec). 
for businesses that want to remain sustainable and competitive over time is cloud computing. Cloud computing allows companies to increase efficiency and decrease operative costs and has become a fundamental tool in the knowledge era, in which strategic decisions are made based on innovative computer tools (Day \& Bens, 2005).

Cloud computing offers to different organizations plenty of opportunities through the Internet to reduce their operational costs while improving their organizational processes. Thus, providing better products and services, and improving business models (Faroughiana et al., 2012).

Companies in the past have traded through large or small supply chains. Technology has offered companies new and more efficient ways to produce, sell, and acquire products, for example, through electronic markets (Zeng, Chen, \& Huang, 2013).

Electronic markets improve the supply chain by avoiding a physical encounter with intermediaries. This is mainly due to the advantages of operating in the cloud (Bermúdez, García, \& Giraldo, 2013). This technological innovation has directly influenced the growth of several companies (Day \& Bens, 2005), by changing their operating models with technology, thus adding value to the business.

For years, cloud computing has appeared as a trendy topic or "new Internet paradigm" that can provide several advantages to a company, such as cost reduction and improved infrastructure maintenance (Moscoso-Zea, 2010). However, the cloud computing adoption is not growing as fast as expected. Researchers believe that this behavior is due to the lack of knowledge and expertise on how to perform a migration from traditional infrastructure to the cloud (Low, Chen, \& Wu, 2011).

This paper presents a novel framework for migrating to the cloud based on best practices and experiences studied in diverse case studies.

\section{Related Work}

\subsection{Cloud computing definition}

Several authors and organizations have given definitions for cloud computing, although the one proposed by the U.S. NIST (National Institute of Standards and Technology) highlights the standard features widely used in the cloud computing community and denotes the key aspects of this concept (Dillon, Wu, \& Chang, 2010):

Cloud computing is a model for enabling convenient, on-demand network access to a shared pool of configurable computing resources (e.g., networks, servers, storage, applications, and services) that can be rapidly provisioned and released with minimal management effort or service provider interaction. (Mell \& Grance, 2011, p. 1).

According to (Amazon, n.d.), cloud computing is the on-demand delivery of computer power, database storage, and other IT resources through a cloud service platform. Amazon adds to their definition the "pay-as-you-go" pricing characteristic, meaning that the organization pays only what they use.

Cloud computing is opposed to the "traditional" on-premise model. Under the onpremise model, the company is responsible for its own IT infrastructure. This has presented several issues limiting the company's growth speed and market potential (Saa, MoscosoZea, Cueva-Costales, \& Lujan-Mora, 2017).

\subsection{Cloud service models}

2.2.1. Software as a Service (SaaS): This model provides software applications through the Internet, using a web browser. The client does not control any infrastructure (network, servers, operating systems, and storage) (Gorelik, 2013). Remarkable examples are Microsoft Office 365, Box.com, and Google Apps among others. SaaS has been criticized by Richard Stallman from the Free Software Foundation. He claims that SaaS 
violates the principles of free software because "the users do not have a copy of the executable file: it is on the server, where the users can't see or touch it" (Stallman, 2010).

2.2.2. Infrastructure as a Service (laaS): It provides a web-based management access to resources such as processing capacity, disk space, and many others. laaS allows the user deploy software in that infrastructure (Gorelik, 2013). Some well-known examples are DigitalOcean, Amazon Web Services (AWS), Google Compute Engine, and Microsoft Azure.

2.2.3. Platform as a Service (PaaS): This model provides a platform and environment to developers enabling them to create applications and services accessible through the Internet (Gorelik, 2013). The infrastructure is managed by the vendor allowing the customer to focus on the products. Some examples of PaaS are Heroku, Apprenda, and many others.

\subsection{Deployment models}

2.3.1. Private cloud: This deployment model provides an exclusive infrastructure to a single organization with multiple employees or customers. It can exist inside or outside the organization.

2.3.2. Community cloud: It is a collaborative environment in which several organizations share the infrastructure from a specific community with common concerns such as security, compliance, and jurisdiction. It can be managed internally or by a thirdparty, and hosted internally or externally.

2.3.3. Public cloud: The cloud infrastructure and resources such as virtual machines, applications or storage are made available to the public through the Internet (Armbrust et al., 2010).

2.3.4. Hybrid cloud: This is a cloud computing environment which uses a mix of onpremise, private cloud, and third-party public cloud services.

\subsection{Existing frameworks for cloud computing adoption}

Through the years, cloud computing has been studied by several authors as a "new and innovative technology" (Dillon, Wu, \& Chang, 2010; Armbrust et al., 2010; Youseff, 2008; Hernandez \& Florez, 2014). These studies focused on cloud computing as a concept, as well as its issues, challenges, evolution, and differentiated characteristics. Recent studies have finally focused on the business perspective and its implications (Day \& Bens, 2005), (Leimeister, Böhm, Riedl, \& Krcmar, 2010).

Several authors have analyzed the available cloud computing models to support cloud computing adoption (Pantelić, Pajić, \& Nikolic, 2016). However, they have not proposed any framework or guidance to carry out the process. Others have studied the cloud computing adoption process in specific industries or institutions such as government agencies or universities (Mokhtar, Al-Sharafi, Ali, \& Al-Othami, 2016; Ezzat, Zanfaly, \& Kota, 2011). Although the proposed frameworks are useful, they are not applicable to every company as they focus on the specific industry or institution requirements.

Varia has proposed a six-step process to migrate existing applications to the AWS Cloud (Varia, 2010). These steps include:

- Cloud assessment phase

- Proof of concept phase

- Data migration phase

- Application migration phase

- Leverage the cloud phase

- Optimization phase

This process leaves out the vendor analysis as well as the cost/benefit assessment as it focus on AWS only. 
Williams proposed a five-step iterative process instead (Williams, 2010). The steps are the following:

- Investigation

- Evaluation

- Decision

- Implementation

- Iteration

That process aims to evaluate a certain service migration. If these steps were accurate and the migration successful, the process would start again with another service.

Saedi divided the cloud computing adoption per phase and proposed three aspects that need to be studied separately (Saedi, 2016):

- Technology: cost-saving, relative advantages, data security, data privacy.

- Organization: size, manager intention, ICT knowledge of employees.

- Environment: competitors, government, IT consultants, business network members.

That framework is only theoretical and serves to identify some barriers for cloud computing adoption, which mainly include the lack of data security, the absence of data privacy, and the size of IT resources (Saedi, 2016). Even though it did not propose any step-by-step process or guidance, the aspect division should be taken into consideration while evaluating the cloud computing adoption.

Eman et al. brought forward a three-layer framework: the first layer is the integration between business, technical, and economic perspectives. The second layer describes the basic factors of each perspective from the first layer. The third layer is a deeper explanation of the factors listed on layer 2 and serves to achieve the goal of assessment and evaluation (Ezzat, Zanfaly, \& Kota, 2011). Once again, it points out some key aspects for the decisionmakers to evaluate before choosing to adopt cloud computing. However, a guidance on how to migrate is missing.

\section{Method}

In a previous study, a six step framework was proposed by studying several proposed frameworks and guidelines for cloud computing adoption. We analyzed their individual strengths and weaknesses to then combine them into a more robust, generic, and implementable framework (Paredes-Gualtor et al., 2017).

Based on the study mentioned above, this paper proposes an additional step to assess cloud computing migration to the chosen provider, considering the same businessfocused framework.

\subsection{Framework proposal}

A seven processes framework is presented in Figure 1 in order to achieve a successful cloud computing migration along with an integrated monitoring solution within edge computing frameworks.

These processes cover the life-span of every cloud computing adoption project and will be described in subsection. 


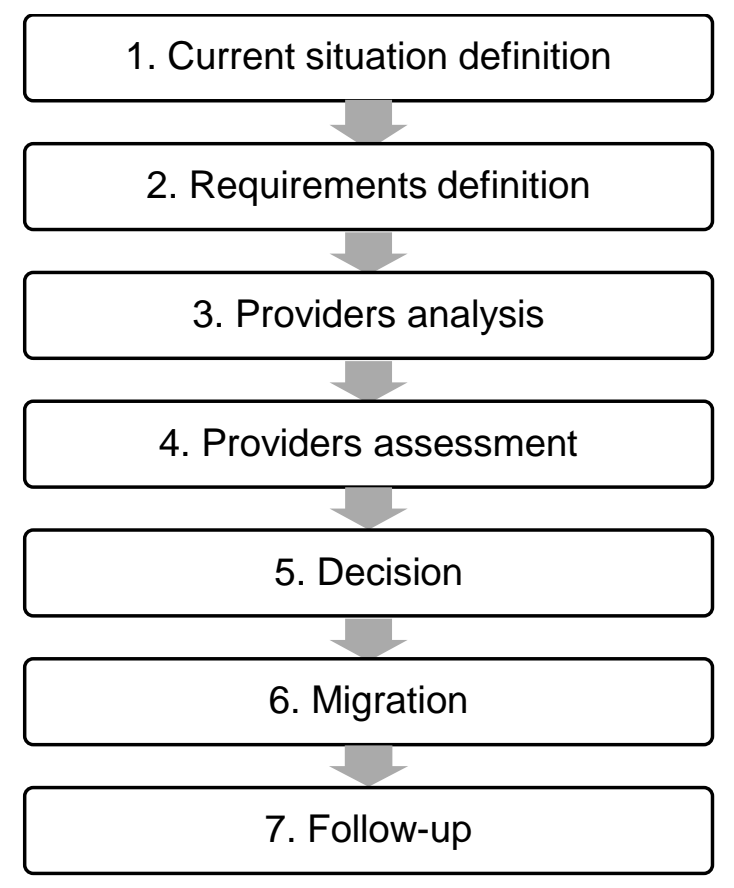

Figure 1. Proposed framework

\subsection{Processes explanation}

\subsubsection{Current situation definition}

As many authors have established, the first step before adopting cloud computing services is to define the company-specific-scenario. This process includes the study of internal (organizational) and external (environmental) characteristics. As stated in the introduction of this paper, we are focusing on the business perspective.

Table 1 describes the proposed characteristics that are to be identified, which are explained as follows:

3.2.1.1. Organizational context

The organizational context describes attributes of the company itself without pointing out the industry, market, or the product they offer.

- Company size: There are several theories on how to determine a company's size. These theories are technological, organizational, and institutional (Kumar, Rajan, \& Zingales, 1999). Certainly, for this category, we are going to use organizational theory. It is important to notice that most studies are mainly empiric, leading us to choose the classification we think is best. The most widely accepted concept to define the company's size is based on the number of employees, and annual revenue (Moeller, Schlingemann, \& MStulz, 2004). Therefore, the categories are described in Table 2.

It is important to mention that there is no formal definition for this categorization. Moreover, the information provided may vary from one country to another.

- Company age: This shows how many years the company has been on the market, and how it has handled its growth as well as market changes. For this, we can identify two categories (Coad, Segarra, \& Teruel, 2016).

- Young: less than 10 years.

- Old: 10 years or more.

Table 1. Company's current situation definition

\begin{tabular}{|l|l|l|}
\hline Category & Attribute & Possible values \\
\hline Organization & Company size & Small and medium-sized businesses \\
\hline
\end{tabular}




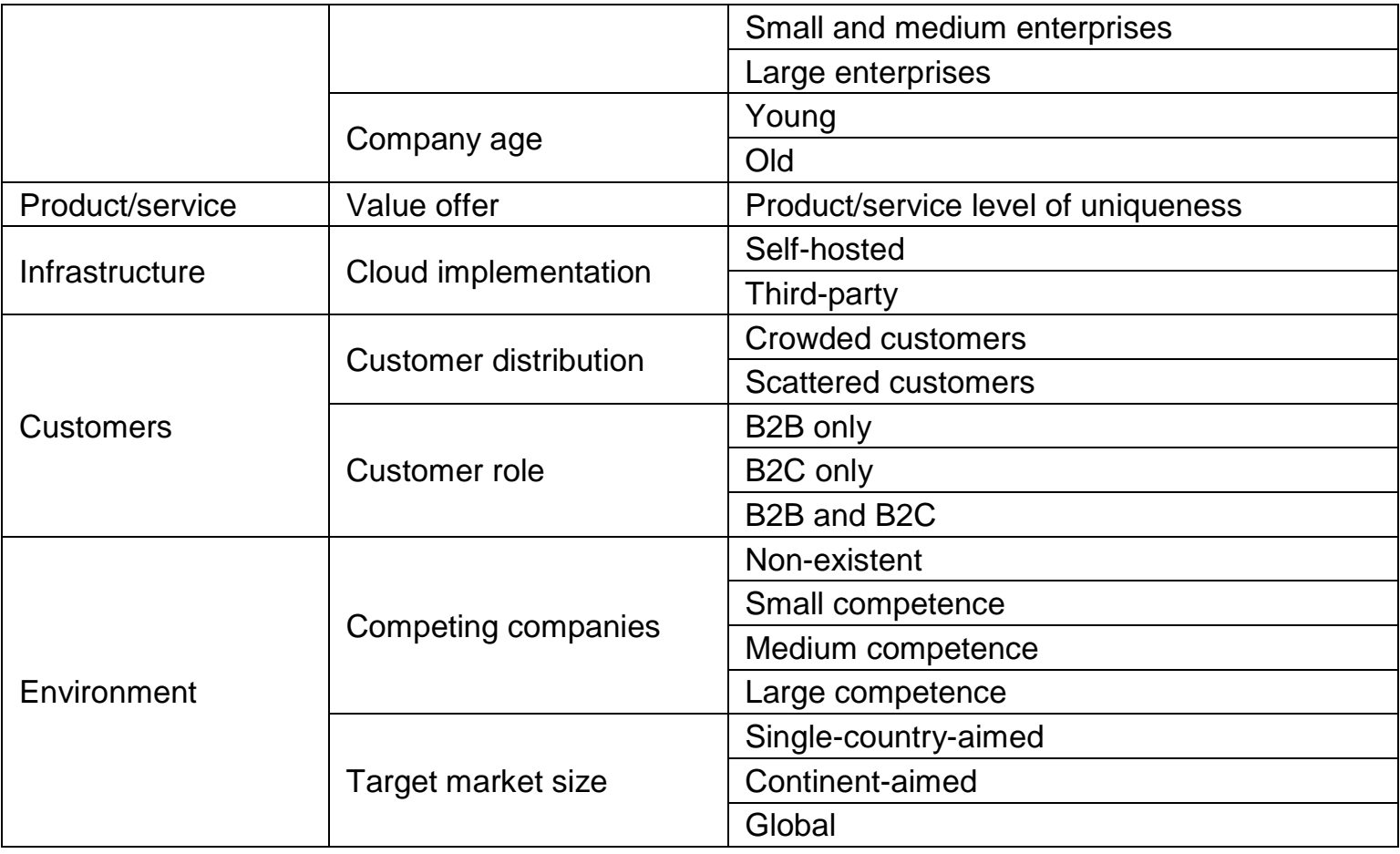

\subsubsection{Product/service}

The products or services each company offers are key differentiators for the cloud service each company may need (Teece, 2010).

\subsubsection{Infrastructure}

It refers to installed network technologies and enterprise systems, which provide a platform on which the cloud computing applications can be built (Low, Chen, \& Wu, 2011). The existing infrastructure defines the migration needs.

\subsubsection{Customers}

The current clients of the company are leading the business in a certain direction. Given the "online" character of the businesses we are studying, it is imperative to know about the following two aspects:

- Customer distribution: whether the customers crowd in a specific area or if they come from different and scattered places.

- Customer role: whether the company's customers are end-customers or other businesses.

\subsubsection{Environment}

The environmental context refers to all the external factors that can affect the company. Competing companies are those which offer the same or a similar service/product, or a substitute product/service. The target market size describes the focus group at which the company aims its marketing efforts.

Table 2. Classification of companies by size

\begin{tabular}{|l|l|l|}
\hline Company Category & Turnover & Employees \\
\hline $\begin{array}{l}\text { Small and Medium-Sized Businesses } \\
(\text { SMB) }\end{array}$ & $\$ 5-\$ 10$ million & $\begin{array}{l}0-100 \text { (small-sized business) } \\
100-999 \text { (medium-sized business) }\end{array}$ \\
\hline Small and Medium Enterprises (SME) & $\$ 10$ million - $\$ 1$ billion & $101-500$ \\
\hline Large Enterprise (LE) & Over $\$ 1$ billion & Over 1000 \\
\hline
\end{tabular}




\subsubsection{Requirements definition}

Before setting the business's objectives, the cloud computing quality-criteria needs to be defined. Choi and Song proposed seven criteria (AICIT, 2012):

- Performance

- Reliability

- Capacity

- Availability

- Security

- Regulations

- Operativity

These criteria must be studied for each service the company needs such as email or file storage.

\subsubsection{Providers Analysis}

Once we have established the company's real situation and its needs, it is time to determine the available alternatives to choose the best provider.

According to Gartner (Leong, Bala, Lowery, \& Smith, 2017), the leading three cloud computing providers are the following:

- Amazon Web Services (AWS)

- Windows Azure

- Google Cloud Platform

\subsubsection{Assessment}

This process aims to validate the business goals with the company's current situation and the provider's alternatives. The aspects to evaluate are:

- Technical feasibility

- Economic feasibility

- Legal feasibility

\subsubsection{Decision}

Several studies describe the different decision models available and evaluate the effectiveness of each of them. The paper entitled "Analysis of available cloud computing models to support cloud computing decision process in an enterprise" has compared several decision-making models (Pantelić, Pajić, \& Nikolic, 2016). We refer the reader to that paper to get more information about the decision process.

\subsubsection{Migration}

Following the decision of switching to a cloud computing provider, the people in charge of the migration need to follow a 7-step process. These steps have been proposed by AWS and adapted to this framework:

- Learn about the cloud computing environment that the company is going to use and get familiar with it.

- Build support among members of the organization.

- Test existing software in the cloud.

- Migrate the company data.

- Migrate the company software applications. 
- $\quad$ Configure security, scalability, and maintenance options.

- Deploy.

Once the company has successfully migrated its data and application to the chosen provider, there are follow-up needs. This was the last step on our first proposed framework (Paredes-Gualtor et al., 2017).

\subsubsection{Follow-up}

Once the migration process is concluded, IT directors will need to make sure everything is working properly. Therefore, the use of the right cloud monitoring technologies is needed to assure the performance of these applications. Recent researches shows that none of the existing widely-used cloud monitoring tools yet provides an integrated monitoring solution within edge computing frameworks (Taherizadeh et al., 2018). Hence, a detailed analysis for both functional and non-functional requirements is provided in order to address all kind of organizations' needs for this step.

These features were investigated in order to find out an appropriate base-line technology for the needs of monitoring applications deployed based on edge computing framework. Table 3 shows a high-level analysis of functional requirements for cloud monitoring tools, while Table 4 a non-functional requirement analysis for cloud monitoring systems. This analysis was the result by comparing ten widely used cloud monitoring tools, both open source and commercial, along with their capabilities and shortcomings, as well as how these monitoring systems meet varied requirements (Taherizadeh et al., 2018).

A detailed analysis of functional requirements for cloud monitoring tools is available at the paper entitled "Monitoring self-adaptive applications within edge computing frameworks: A state-of-the-art review" (Taherizadeh et al., 2018). We refer the reader to that paper to find more detailed information about this process.

\section{Conclusions}

Organizations that want to remain competitive over time should start thinking in a cloud migration process. If a sound method is in the center of the migration process, the outcomes of this change can bring much and better benefits for organizations. This paper proposes a framework for the migration which is meant to support organizations to implement cloud computing services with best practices at the lowest risk. The main goal of the framework is to improve the migration process by minimizing threats and maximizing opportunities.

This unified framework consists in a well-defined 7-step process which has been improved after its application in the telecommunication industry (see Figure 1). Furthermore, this improved framework can be adopted by any organization, no matter the size, age or industry, as long as all the provided guidelines are followed. In addition, the main weaknesses and threats to this new approach are security and integrity risks to the data stored in the system (Saa, Moscoso-Zea, Cueva-Costales, \& Lujan-Mora, 2017). These concerns are not discussed in this paper but can be reviewed at (Saa, Cueva-Costales, Moscoso-Zea, \& Luján-Mora, 2017).

This study responds to previous researches suggested by other authors, in order to develop a complete risk and control framework for cloud computing. Which provides management with guidelines and control standards to deal coherently with cloud computing including the follow-up after migration. (Carroll, Merwe, \& Kotze, 2011).

We hope that this approach supports IT directors in the management of IT assets and business analysts to reduce uncertainty in the construction and implementation of new technologies. 
Table 3. High-level analysis of functional requirements. Adapted from: (Taherizadeh et al., 2018)

\begin{tabular}{|l|l|l|l|l|l|l|l|l|l|}
\hline Tool & $\begin{array}{l}\text { Open } \\
\text { source }\end{array}$ & License & Collection & $\begin{array}{l}\text { VM } \\
\text { monito } \\
\text { ring }\end{array}$ & $\begin{array}{l}\text { Container } \\
\text { monitoring }\end{array}$ & $\begin{array}{l}\text { End-to-end } \\
\text { link quality } \\
\text { monitoring }\end{array}$ & $\begin{array}{l}\text { Application } \\
\text { monitoring }\end{array}$ & $\begin{array}{l}\text { Data } \\
\text { storage } \\
\text { method }\end{array}$ & GUI \\
\hline Ganglia & Yes & GPL & Pull & Yes & Yes & Yes & $\begin{array}{l}\text { ZODB } \\
\text { Maria DB } \\
\text { HBase } \\
\text { MySQL }\end{array}$ & Yes \\
\hline Zabbix & Yes & GPL & Push/Pull & Yes & Yes & Yes & Yes & $\begin{array}{l}\text { MySQL } \\
\text { PostgreSQL } \\
\text { SQLite }\end{array}$ & Yes \\
\hline Nagios & Yes & GPL & Pull & Yes & No & Yes & No & $\begin{array}{l}\text { Flat file } \\
\text { MySQL }\end{array}$ & Yes \\
\hline OpenNebula & Yes & Apache2 & Push/Pull & Yes & No & No & No & $\begin{array}{l}\text { SQLite } \\
\text { MySQL } \\
\text { Apache } \\
\text { Cassandra }\end{array}$ & Yes \\
\hline PCMONS & Yes & NewBSD & Pull & Yes & No & No & No & $\begin{array}{l}\text { Flat file } \\
\text { MySQL }\end{array}$ & Yes \\
\hline DARGOS & Yes & Apache2 & Push/Pull & Yes & No & No & Yes & $\begin{array}{l}\text { Nova } \\
\text { Neutron DB }\end{array}$ & Yes \\
\hline Lattice & Yes & Apache2 & Push & Yes & Yes & No & Yes & $\begin{array}{l}\text { Distributed } \\
\text { Hash Table }\end{array}$ & No \\
\hline JCatascopia & Yes & Apache2 & Push/Pull & Yes & No & No & Yes & $\begin{array}{l}\text { Apache } \\
\text { Cassandra } \\
\text { MySQL }\end{array}$ & Yes \\
\hline $\begin{array}{l}\text { Tower } \\
\text { 4Clouds }\end{array}$ & Yes & Apache2 & Push & Yes & No & No & Yes & $\begin{array}{l}\text { Influx DB } \\
\text { Graphite }\end{array}$ & Yes \\
\hline
\end{tabular}

Table 4. Analysis of non-functional requirements. Adapted from: (Taherizadeh et al., 2018)

\begin{tabular}{|l|l|l|l|l|l|}
\hline Tool & Scalability & Robustness & Non-intrusiveness & Interoperability & $\begin{array}{l}\text { Live-migration } \\
\text { support }\end{array}$ \\
\hline Zenoss & Yes & No & Yes & Yes & No \\
\hline Ganglia & Yes & Yes & Limited & Yes & Yes \\
\hline Zabbix & Yes & No & Yes & Yes & No \\
\hline Nagios & No & No & Limited & Yes & No \\
\hline OpenNebula & Yes & Yes & Yes & No & Limited \\
\hline PCMONS & No & No & Limited & Yes & No \\
\hline DARGOS & Yes & No & Yes & No & No \\
\hline Lattice & Yes & Yes & Yes & Yes & Yes \\
\hline JCatascopia & Yes & Yes & Limited & Yes & Yes \\
\hline Tower 4Clouds & Yes & Yes & Limited & Yes & Yes \\
\hline
\end{tabular}

\section{Acknowledgments}

A previously performed research turned out into a 6-step framework to guide any organization in the cloud computing adoption process (Paredes-Gualtor, Moscoso-Zea, Saa, Sandoval, \& Rodas, 2017). This initial version was published as "Unified Cloud Computing Adoption Framework", in the 2017 International Conference on Information Systems and Computer Science (INCISCOS).

As the framework came in use, we noticed the importance to add a follow-up step after the migration process.

\section{References}

AICIT. (2012). Relative weight Decision of Quality Attributes in Cloud Computing Service Using ANP. International Journal in Advance Computer Technology, 4, 240-248.

Armbrust, M., Fox, A., Griffith, R., Joseph, A. D., Katz, R., Konwinski, A., . . Zaharia, M. (2010). A View of Cloud Computing. Communications of the ACM, 53(4), 50-58. 
Bermúdez, G. T., García, V. H., \& Giraldo, L. (2013). Implementation Models of Electronic Commerce Solutions. Revista Ingenierías.

Carroll, M., Merwe, A. V., \& Kotze, P. (2011). Secure cloud computing: Benefits, risks and controls. Information Security for South Africa, (pp. 1-9). Johannesburg.

Coad, A., Segarra, A., \& Teruel, M. (2016). Innovation and firm growth: Does firm age play a role? Research Policy, 45(3), 387-400.

Day, G. S., \& Bens, K. J. (2005). Capitalizing on the internet opportunity. Journal of Business \& Industrial Marketing, 20(160-168), 160-168.

Dillon, T., Wu, C., \& Chang, E. (2010). Cloud Computing: Issues and Challenges. 24th IEEE International Conference on Advanced Information Networking and Applications (AINA) (pp. 27-33). Perth: IEEE.

Ezzat, E. M., Zanfaly, D. S., \& Kota, M. M. (2011). Fly over clouds or drive through the crowd: A cloud adoption framework. International Conference and Workshop on Current Trends in Information Technology (CTIT), (pp. 6-11). Dubai.

Faroughiana, F. F., Kalafatis, S. P., Ledden, L., Samouel, P., \& Tsogas, M. H. (2012). Value and Risk in Business-To-Business e-Banking. Industrial Marketing Management, 68-81.

Gorelik, E. (2013). Cloud Computing Models. Cambridge: Massachusetts Institute of Technology.

Hernandez Quintero, N. L., \& Florez Fuente, A. S. (2014). Cloud Computing. Mundo FESC, 2(8), 46-51.

Kumar, K. B., Rajan, R. G., \& Zingales, L. (1999, July). What Determines Firm Size? National Bureau of Economic Research, p. 54.

Leimeister, S., Böhm, M., Riedl, C., \& Krcmar, H. (2010). The Business Perspective of Cloud Computing: Actors, Roles and Value Networks. ECIS, 56.

Leong, L., Bala, R., Lowery, C., \& Smith, D. (2017). Magic Quadrant for Cloud Infraestructure as a Service, Worldwide. Gartner.

Low, C., Chen, Y., \& Wu, M. (2011). Understaning the Determinants of Cloud Computing Adoption. 111(7).

Mell, P., \& Grance, T. (2011, July 09). The NIST Definition of Cloud Computing: Recommendations of the National Intitute of Standars and Technology.

Moeller, S. B., Schlingemann, F. P., \& MStulz, R. (2004). Firm size and the gains from acquisitions. Journal of Financial Economics, 73(2), 201-228.

Mokhtar, S. A., Al-Sharafi, A., Ali, S. H., \& Al-Othami, A. Z. (2016). Identifying the determinants of cloud computing adoption in higher education institutions. International Conference on Information and Communication Technology (ICICTM), (pp. 115-119). Kuala Lumpur.

Moscoso-Zea, O. (2010). Megastore: structured storage for Big Data. Enfoque UTE, 1-12.

Pantelić, O., Pajić, A., \& Nikolic, A. (2016). Analysis of available cloud computing models to support cloud adoption decision process in an enterprise. 6th International Conference on Computers Communications and Control (ICCCC) (pp. 135-139). Oradea: International Conference on Computers Communications and Control.

Paredes-Gualtor, J., Moscoso-Zea, O., Saa, P., Sandoval, F., \& Rodas, P. (2017). Unified Cloud Computing Adoption Framework. 2nd International Conference on Information Systems and Computer Science (INCISCOS).

Saa, P., Cueva-Costales, A., Moscoso-Zea, O., \& Luján-Mora, S. (2017). Moving ERP Systems to the Cloud - Data Security Issues. Journal of Information Systems Engineering \& Management, 1-9.

Saa, P., Moscoso-Zea, O., Cueva-Costales, A., \& Lujan-Mora, S. (2017). Data Secutiry issues in Cloud-Bases Software-as-a-Service ERP. 12th Iberian Conference on Information Systems and Technologies (CISTI), 1-7.

Saedi, A. (2016). Cloud computing adoption framework: Innovation translation approach. 3rd International Conference on Computer and Information Sciences (ICCOINS), (pp. 153-157). Kuala Lumpur. 
Taherizadeh, S., Jones, A. C., Taylor, I., Zhao, Z., \& Stankovski, V. (2018). Monitoring self-adaptive applications within edge computing frameworks: A state-of-the-art review. The Journal of Systems and Software, 19-38.

Teece, D. J. (2010). Business Models, Business Strategy and Innovation. Long Range Planning, 43(2-3), 172-194.

Varia, J. (2010). Migrating your Existing Applications to the AWS Cloud. Amazon Web Services.

Williams, M. I. (2010). A quick start guide to cloud computing: moving your business into the cloud. London: Paperback.

Youseff, L. B. (2008). Toward a Unified Ontology of Cloud Computing. Grid Computing Environments Workshop, 1-10.

Zeng, Q., Chen, W., \& Huang, L. (2013). Trends in E-Business, E-Services, and ECommerce: Impact of Technology on Goods, Services, and Business Transactions. Illinois: Western Illinois University. 